\title{
Caracterização de processos hidrogeoquímicos em águas subterrâneas do Sistema Aquífero Santa Maria, na região central do Rio Grande do Sul
}

\author{
Characterization of hydrogeochemical processes in groundwater of Santa Maria Aquifer \\ System, in the central region of Rio Grande do Sul
}

Thiago Boeno Patricio Luiz e José Luiz Silvério da Silva

Universidade Federal de Santa Maria

thiagoboeno@hotmail.com - http://orcid.org/0000-0002-7054-1780

silveriufsm@gmail.com - http://orcid.org/0000-0003-1712-9145

\section{Resumo}

Conduziu-se um estudo sobre os processos hidrogeoquímicos envolvendo as águas subterrâneas da porção oeste do Sistema Aquifero Santa Maria (SASM), na região central do Rio Grande do Sul. O trabalho objetivou caracterizar comportamentos de uma parcela das águas subterrâneas entre os municípios de São Pedro do Sul, Santa Maria e Restinga Seca, com base em um modelo entre interação água/rocha. Foram analisadas informações mineralógicas e hidroquímicas, buscandose modelar a evolução hidrogeoquímica do aquifero nesses municípios. Para tanto, executou-se o processamento das informações levantadas em um código de modelagem geoquímico, utilizando como referência estudos mineralógicos realizados anteriormente. Os resultados apontaram as principais interações geoquímicas responsáveis pelo quimismo da água subterrânea, que é fortemente dependente da composição química das águas de recarga e do aporte mineralógico das rochas sedimentares deste sistema aquifero. Os estados de saturação das águas subterrâneas demonstraram processos de subsaturação tendendo ao equilíbrio de minerais carbonáticos, indicando a dissolução desses minerais, principalmente a calcita, bem como supersaturação dos argilo-minerais ilita, montmorillonita (esmectita) e caulinita, em ambos os casos tendendo para a alcalinização do meio. A caracterização quanto às propriedades hidrogeoquímicas dos aquíferos são importantes para um correto entendimento dos processos que nele ocorrem e que dominam a hidrogeologia regional.

Palavras-chave: Hidrogeoquímica; Àgua subterrânea; Modelo água/rocha

\section{Abstract}

A study was carried out of the hydrogeochemical processes involving the groundwater of the western portion of the Santa Maria Aquifer System (SMAS) in the central region of Rio Grande do Sul. The objective of this study was to characterize the behavior of a portion of the groundwater between São Pedro do Sul, Santa Maria and Restinga Seca municipalities, based on a model between water/rock interaction. Mineralogical and hydrochemical information were analyzed, aiming to model the hydrogeochemical evolution of the aquifer in these municipalities. For this purpose, a processing of the information in a geochemical modeling code was performed, using as previous reference mineralogical studies. The results pointed out the main geochemical interactions responsible for groundwater chemistry, which is strongly dependent of the chemical composition of the recharge waters and the mineralogical contribution of the sedimentary rocks of this aquifer system. The groundwater saturation states showed subsaturation processes tending to the balance of carbonate minerals, indicating the dissolution of these minerals, mainly calcite, as well as supersaturation of clay-minerals ilite, montmorillonite (smectite) and kaolinite, in both cases tending to the alkalinization of the environment. The characterization of the hydrogeochemical properties of aquifers is important for a correct understanding of the processes that occur in it and dominate the regional hydrogeology

Keywords: Hydrogeochemistry; Groundwater; Water/rock model 


\section{Introdução}

Os recursos hídricos subterrâneos são elementos intrínsecos ao ciclo hidrológico, onde o conhecimento das suas características hidroquímicas são fundamentais para a compreender sua dinâmica no meio. Em relação à composição química da água subterrânea, esta demonstra guardar uma relação direta com os tipos de rochas drenadas. Neste contexto, os estudos hidrogeoquímicos são importantes, pois oferecem informações sobre a origem dos elementos químicos dissolvidos nas águas.

O Sistema Aquífero Santa Maria (SASM), localizado no sul do Brasil, possui relevante importância ambiental e econômica para o Estado do Rio Grande do Sul, uma vez que é um dos principais recursos hídricos utilizados para explotação de água para consumo na região central. Este sistema aquífero faz parte do Sistema Aquífero Guarani (SAG), na região conhecida como Zona de Afloramentos (ZA) (PSAG/OEA/PEA, 2009).

As características estratigráficas e mineralógicas do SASM vêm sendo documentadas ao longo dos anos por diversos autores como Silvério da Silva (1997), Silvério da Silva e Menegotto (2002; 2005), Silvério da Silva et al. (1990), Giardin, e Faccini (2004), Maciel Filho (1990), Machado e Freitas (2005), onde foram realizados o detalhamento das fases minerais em amostras de materiais silicosos das rochas sedimentares.

Estudos hidroquímicos desenvolvidos por Silvério da Silva et al. (2000), Machado e Freitas (2005), Terra (2015) e Luiz et al. (2015) salientam sobre a predominância dos íons bicarbonato e sódio ou bicarbonato e cálcio em solução, em várias amostras de águas subterrâneas desses municípios e em ZA do SAG. Partindo-se da ótica hidrogeológica, organizou-se um inventário contendo informações mineralógicas do SASM bem como 36 análises químicas representativas desse sistema aquífero entre os municípios de São Pedro do Sul, Santa Maria e Restinga Seca, com o intuito de avaliar em primeiro momento sua confiabilidade analítica e posteriormente proceder para o processamento dos dados.

A base metodológica deste artigo consiste, principalmente, em realizar cálculos de especiação química em resultados de análises hidroquímicas de água subterrânea com bom grau de confiança analítica, aliados a dados mineralógicos a fim de identificar os processos geoquímicos que decorrem no meio com relação aos seus minerais constituintes. Para tanto, utilizaram-se os íons maiores (sódio, cálcio, potássio, magnésio, cloreto, bicarbonato e sulfato), além do silicato, do ferro total e do alumínio total, buscando-se assim, traçar comportamentos de dissolução e precipitação no meio e consequente evolução hidrogeoquímica.

O presente estudo apresenta como resultado uma interpretação dos processos hidrogeoquímicos que ocorrem nas águas subterrâneas do SASM na ZA do SAG, utilizando-se os cálculos de especiação química das águas como indicadores matemáticos que expliquem os comportamentos característicos deste aquífero em escala de município.

O resultado desta análise apresenta os índices de saturação (IS) de minerais constituintes das unidades aquíferas, indicando assim, o estado de distribuição das espécies iônicas em solução. Dessa forma, este trabalho visa identificar as homogeneidades que caracterizam as dinâmicas hidrogeoquímicas do SASM, fornecendo subsídios para uma melhor compreensão dos processos que nele ocorrem e fornecendo à comunidade hidrogeológica uma visão da dinâmica geoquímica deste sistema aquífero. 


\section{Materiais e métodos}

\subsection{Localização e descrição da área de estudo}

Geomorfologicamente, os municípios de São Pedro do Sul, Santa Maria e Restinga Seca estão localizados na Depressão Central do Estado do Rio Grande do Sul, abrangendo parcialmente as bordas das rochas vulcânicas da Formação Serra Geral (Figura 1). As litologias areníticas dos municípios fazem parte da ZA do SAG. (PSAG/OEA/PEA, 2009).

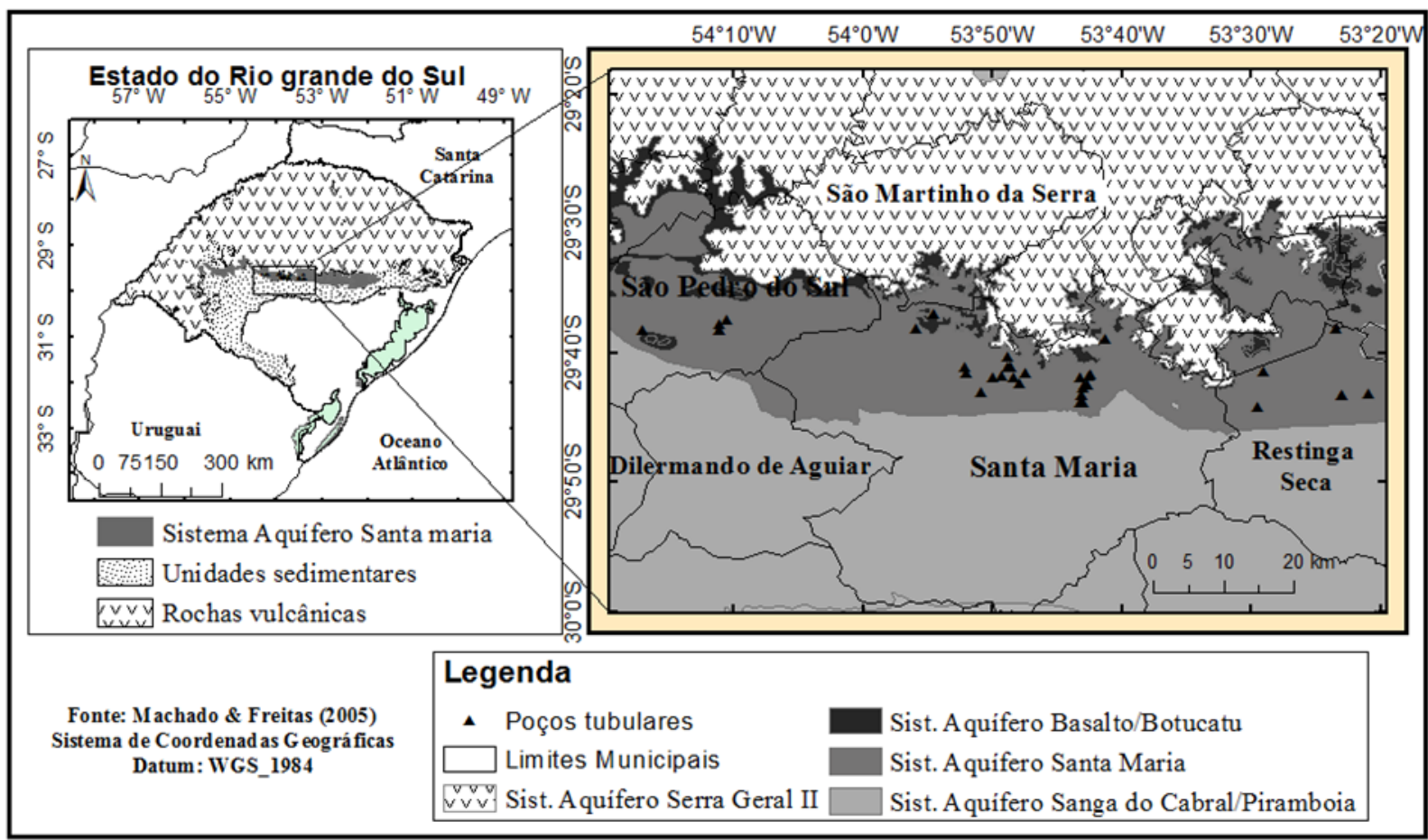

Figura 1 - Localização da área de estudo com mapa hidrogeológico simplificado

As litologias da formação Santa Maria ocorrem na borda da Bacia do Paraná e fazem parte do grupo Rosário do Sul, onde de acordo com Giardin e Faccini (2004) é delimitada na base por uma superfície erosional sobre a qual se depositam os arenitos de canais fluviais do membro Passo das Tropas e, no topo, litofácies pelíticas de planícies de inundação, ricos em vertebrados fósseis e horizontes de paleossolos, conhecido como membro Alemoa podendo formar o aquiclude Alemoa cuja capacidade aquífera é muito baixa.

\subsection{Características mineralógicas do SASM}

Estudos mineralógicos e petrográficos desenvolvidos por Silvério da Silva (1997) e Silvério da Silva e Menegotto $(2002 ; 2005)$ através de análise de perfis de rochas sedimentares fluviais da Formação Santa Maria (Membro Passo das Tropas), de idade Triássica superior mostraram que o constituinte principal da matriz rochosa é o quartzo microcristalino, com dimensões em torno de $1 \mu \mathrm{m}$, observados em microscopia eletrônica de varredura (MEV) e, em menor proporção, ocorre sílica fibrosa (calcedonita) e megaquartzo (quartzo cristalino). 
Na parte inferior do perfil ocorrem arenitos muito finos com diâmetro em torno de $0,02 \mathrm{~m}$. A parte superior do perfil é constituída por siltitos não silicificados contendo 5 níveis de crostas silicosas e/ou silcretes típicos. No topo do perfil ocorre um nível conglomerático de cor vermelha ou marrom escura, possivelmente cenozóico, que contem fragmentos de silcrete, seixos de quartzo e de calcedônia. (SILVÉRIO DA SILVA; MENEGOTTO, 2005)

Os argilo-minerais presentes nessa formação são argilas esmectitas, expansivas, secundariamente do tipo interestratificado I/S (ilita/esmectita) com aspecto filamentoso e também ocorrem as caulinitas. Da mesma forma, uma amostra dessa unidade aquífera no município de Santa Cruz do Sul, localizado a $90 \mathrm{~km}$ da área de estudo, apresentou microcristais de halita e silvita observados com microscopia eletrônica de varredura (MEV) e energia dispersiva de raios-x (EDS).

\subsection{Características hidroquímicas do SASM e modelo de especiação utilizado}

De acordo com Machado e Freitas (2005), a composição hidroquímica das águas subterrâneas do SASM comportam um predomínio do ânion bicarbonato sobre os demais e os cátions tendem a ter um caráter mais sódico. Contudo, em menor proporção podem ser encontradas águas bicarbonatadas cálcicas, mistas tendendo a sódicas, e, em menor proporção cloretadas sódicas.

Em primeiro momento, foram inventariados 36 poços tubulares entre os municípios com informações hidroquímicas e geológicas a partir do Sistema de Informações de Águas Subterrâneas (SIAGAS) (SIAGAS, 2016) do Serviço Geológico do Brasil (CPRM). A tabela 1 mostra a estatística descritiva básica das principais características hidroquímicas das águas subterrâneas nas análises químicas inventariadas.

Tabela 1 - Características hidroquímicas de 36 análises da água subterrânea do SASM expressas em mg/L

\begin{tabular}{cccll}
\hline Parâmetro & Mínima & Máxima & Média & $\begin{array}{c}\text { Desvio } \\
\text { Padrão }\end{array}$ \\
\hline $\mathrm{pH}$ & 5,41 & 10,10 & 7,35 & 1,18 \\
$\mathrm{Na}^{+}$ & 2,24 & 640,00 & 37,00 & 106,3 \\
$\mathrm{~K}^{+}$ & 0,10 & 7,40 & 2,45 & 1,99 \\
$\mathrm{Ca}^{2+}$ & 0,60 & 73,00 & 6,00 & 15,54 \\
$\mathrm{Mg}_{2+}$ & 0,003 & 29,10 & 1,05 & 4,81 \\
$\mathrm{Cl}^{-}$ & 0,10 & 71,04 & 6,94 & 14,49 \\
$\mathrm{HCO}_{3}{ }^{-}$ & 11,05 & 669,00 & 135,00 & 112,2 \\
$\mathrm{SO}_{4}^{2-}$ & 0,05 & 80,70 & 6,26 & 20,1 \\
$\mathrm{Alcalinidade}$ & 9,06 & 548,00 & 129,00 & 93,82 \\
$\mathrm{Al}$ & 0,005 & 4,70 & 0,07 & 1,03 \\
$\mathrm{Fe}$ & 0,005 & 1,60 & 0,10 & 0,31 \\
$\mathrm{SiO}_{2}$ & 3,03 & 62,6 & 21,00 & 16,43 \\
$\mathrm{~F}^{-}$ & 0,005 & 1,20 & 0,15 & 0,27 \\
$\mathrm{Prof} .(\mathrm{m})$ & 52,00 & 156,00 & 90,00 & 28,09 \\
$\mathrm{CE}(\mu \mathrm{S} / \mathrm{cm})$ & 37,90 & 1100,00 & 269,50 & 201,77 \\
\hline
\end{tabular}


Notar na tabela as profundidades dos poços tubulares, variando de 52 a 156 metros e, a faixa de valores de $\mathrm{pH}$ variando entre ácido até fortemente alcalino. A alcalinidade do meio varia amplamente entre 9,06 a 548,0 mg/L, assim como os valores de $\mathrm{pH}$, que variaram de muito ácido $(\mathrm{pH}=5,41)$ a muito alcalino $(\mathrm{pH}=10,10)$. O diagrama de Piper da figura 2 demonstra as ocorrências predominantemente bicarbonatadas pelo lado dos ânions e a predominância cálcica ou sódica tendendo a sódica pelo lado dos cátions.

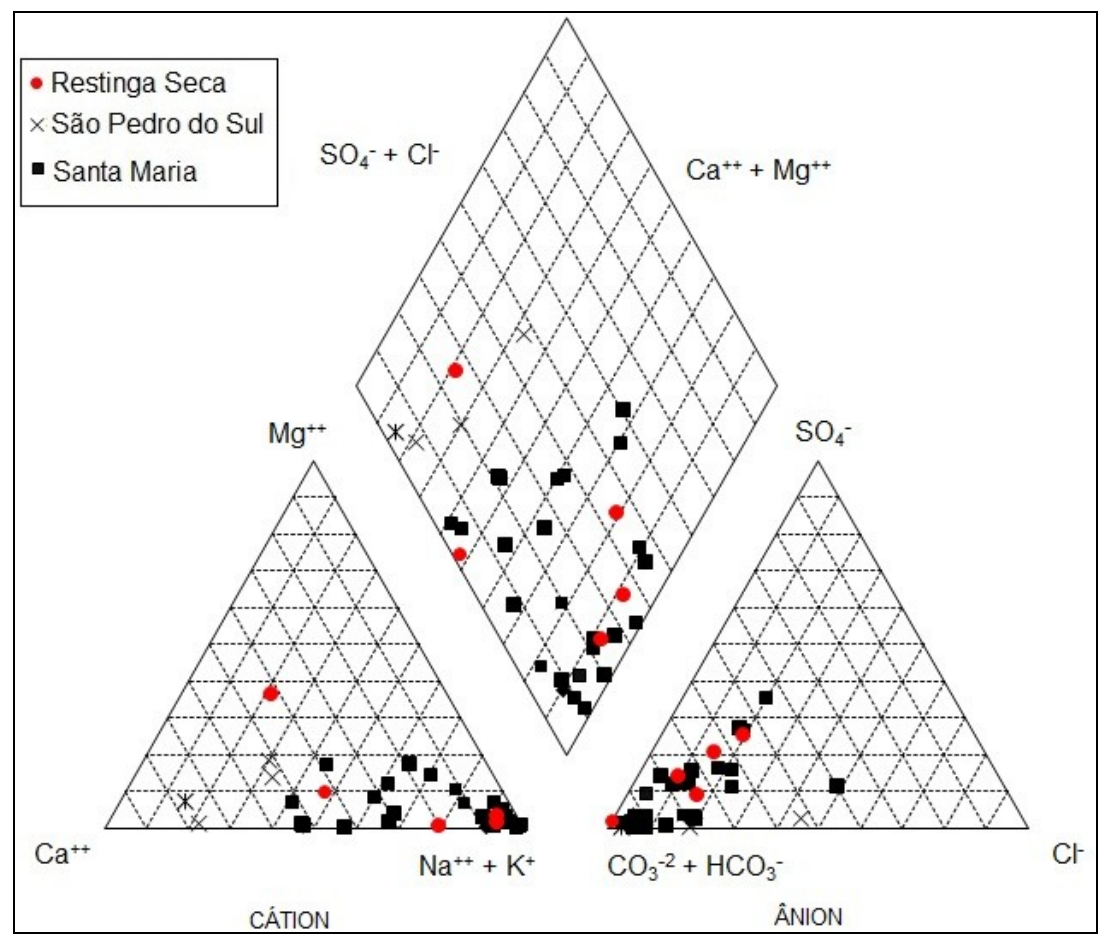

Figura 2 - Diagrama de Piper com as 36 análises químicas inventariadas

A partir das informações levantadas, partiu-se para o tratamento e interpretação dos dados através da modelagem do equilíbrio entre o sólido e a fase aquosa em reações de dissolução/precipitação. Essas informações aliadas a dados geológicos dos tipos de constituintes da matriz são muito úteis para estabelecer padrões de funcionamento, e, posteriormente, construir uma representação em ambiente de codificação.

Para modelagem geoquímica, foram analisados o grau de confiabilidade das análises quanto às características hidroquímicas por meio da avaliação do erro residual, que é obtida através da soma dos cátions e ânions em miliequivalentes/Litro (LOGAN, 1965). Como critério, as análises químicas avaliadas foram águas subterrâneas cujos erros fiquem menores que $10 \%$, onde buscou-se dados confiáveis do ponto de vista analítico. Após essa verificação, foram selecionadas 11 análises hidroquímicas principais para caracterizar mecanismos que permitem o enriquecimento dos íons na água subterrânea, denominados AH1 a AH11.

Além dos cátions e íons maiores, foram inseridos na análise a concentração de silicato, ferro total e alumínio total, uma vez que são elementos comuns em minerais que fazem parte do aquífero (SILVÉRIO DA SILVA; MENEGOTTO 2002; 2005) e são importantes traçadores que auxiliam na interpretação geoquímica. Esses elementos na forma mineral podem estar associados a materiais de desagregação, podendo ser responsáveis pela liberação de elementos no meio. 
A modelagem hidrogeoquímica foi realizada pela construção de um código que utilizou os parâmetros das análises químicas selecionadas como vetores, aplicando-se posteriormente para leitura no software PHREEQC 3.3.5 (PARKHURST; APPELO, 1999). A abordagem que é utilizada por este software para simular as interações água-gásrocha é alicerçada principalmente na teoria de associação iônica (MERKEL; PLANNER FRIEDRICH, 2012).

Utilizou-se os bancos de dados phreeqc.dat e minteq.dat, buscando-se avaliar o IS da solução com respeito ao mineral constituinte e verificando se o equilíbrio mineral está favorável aos processos de dissolução ou precipitação. $\mathrm{O}$ IS mineral em meio aquoso é considerado como o logaritmo do quociente entre o produto da atividade iônica (ou produto das atividades elementares) e o produto da sua solubilidade máxima possível (baseada em dados equilíbrio obtidos da literatura) (MERKEL; PLANNER FRIEDRICH, 2012). O IS indica, portanto, se a solução está em equilíbrio (IS $\approx 0$ ), subsaturada em solução (IS $<0$ ) ou supersaturada em solução (IS $>0$ ) com respeito a algum mineral. As formas minerais utilizadas para realizar as simulações bem como a fonte de dados de equilíbrio químico utilizado para cada mineral, estão discriminadas no quadro 1.

Quadro 1- Forma mineral considerada

\begin{tabular}{|c|c|c|}
\hline Forma & Mineral & \\
\hline $\mathrm{CaCO}_{3}$ & Aragonita $^{1}$ & \multirow{3}{*}{ Carbonato } \\
\hline $\mathrm{CaCO}_{3}$ & Calcita $^{1}$ & \\
\hline $\mathrm{FeCO}_{3}$ & Siderita $^{1}$ & \\
\hline $\mathrm{CaSO}_{4}$ & Anidrita $^{1}$ & \multirow{5}{*}{ Sulfato } \\
\hline $\mathrm{CaSO}_{4}: 2 \mathrm{H}_{2} \mathrm{O}$ & Gipso $^{1}$ & \\
\hline $\mathrm{FeSO}_{4}: 7 \mathrm{H}_{2} \mathrm{O}$ & Melanterita $^{1}$ & \\
\hline $\mathrm{KFe} 3\left(\mathrm{SO}_{4}\right) 2(\mathrm{OH})_{6}$ & Jarosita-k $^{1}$ & \\
\hline $\mathrm{KAl}_{3}\left(\mathrm{SO}_{4}\right)_{2}(\mathrm{OH})_{6}$ & Alunita $^{1}$ & \\
\hline $\mathrm{Al}(\mathrm{OH})_{3}$ & Hidróxido de alumínio $^{1}$ & \multirow{3}{*}{ Alumínio } \\
\hline $\mathrm{Al}(\mathrm{OH})_{3}$ & Gibbsita $^{1}$ & \\
\hline $\mathrm{A}_{2} \mathrm{O}_{3}$ & Óxido de alumínio ${ }^{2}$ & \\
\hline $\mathrm{NaAlSi}_{3} \mathrm{O}_{8}$ & Albita $^{1}$ & \multirow{6}{*}{$\begin{array}{l}\text { Alumino- } \\
\text { silicatos }\end{array}$} \\
\hline $\begin{array}{l}\mathrm{K}_{0.6} \mathrm{Mg}_{0.25} \mathrm{Al}_{2.3} \\
\mathrm{Si}_{3.5} \mathrm{O}_{10}(\mathrm{OH})_{2}\end{array}$ & Illita $^{1}$ & \\
\hline $\mathrm{KAlSi}_{3} \mathrm{O}_{8}$ & Feldspato-k $^{1}$ & \\
\hline $\mathrm{KAl}_{3} \mathrm{Si}_{3} \mathrm{O}_{10}(\mathrm{OH})_{2}$ & Mica-k $^{1}$ & \\
\hline $\mathrm{Al}_{2} \mathrm{Si}_{2} \mathrm{O}_{5}(\mathrm{OH})_{4}$ & Caulinita $^{1}$ & \\
\hline $\begin{array}{c}\mathrm{Mg}_{0.48} \mathrm{Fe}_{.22} \mathrm{Al}_{1.71} \\
\mathrm{Si}_{3.81} \mathrm{O}_{10}(\mathrm{OH})_{2}\end{array}$ & Montmorillonita (Esmectita) ${ }^{2}$ & \\
\hline $\mathrm{Fe}(\mathrm{OH})_{3}$ & $\mathrm{Fe}(\mathrm{OH})_{3}{ }^{1}$ & \multirow{3}{*}{ Ferro } \\
\hline $\mathrm{FeOOH}$ & Goethita $^{1}$ & \\
\hline $\mathrm{Fe}_{2} \mathrm{O}_{3}$ & Hematita $^{1}$ & \\
\hline $\mathrm{NaCl}$ & Halita $^{1}$ & \multirow{2}{*}{ Sais } \\
\hline $\mathrm{KCl}$ & Sylvita $^{1}$ & \\
\hline
\end{tabular}

1- phreeqc.dat; 2 - minteq.dat

Notar do quadro 1 que a maioria dos minerais utilizados são provenientes do banco de dados phreeqc.dat, sendo somente utilizado o minteq.dat para os cálculos do óxido de alumínio e o mineral esmectita. Os dados do phreeqc.dat foram utilizados como banco de dados padrão para a maioria dos cálculos realizados, uma vez que o espectro de aplicações do phreeqc.dat é muito mais amplo (MERKEL; PLANNER FRIEDRICH, 2012), contudo, esse banco de dados não possui os dados de equilíbrio químico necessário para as reações que envolvem o mineral esmectita e o óxido de alumínio. 


\section{Resultados e discusão}

\subsection{Minerais carbonatados}

Nas águas subterrâneas os principais componentes da alcalinidade são principalmente os bicarbonatos, carbonatos e os hidróxidos. Os mais representativos são os bicarbonatos e, em menor quantidade os carbonatos, que são menos solúveis, mas se encontram em teor considerável para $\mathrm{pH}>8,3$ (LOGAN, 1965). As análises com $\mathrm{pH}$ maior que 8,3 apresentam além dos íons bicarbonato o íon carbonato, o qual pode associar-se as ocorrências de concreções carbonáticas e calcretes. Uma vez que os cimentos calcíticos podem sofrer dissolução e/ou reprecipitação retirando os íons carbonato do meio aquoso e passando para o mineral.

Fato observado na região é a deposição de cimento calcítico em tubos de plástico em poços tubulares. Outra característica é a formação de concreções no fundo de chaleiras metálicas quando do processo de fervura da água favorecem a precipitação de bicarbonatos. Muitas vezes ainda ocorre a precipitação de concreções carbonáticas em resistências de chuveiros que utilizam águas subterrâneas. Esse comportamento foi observado nas unidades hidroestratigráficas do SASM por Silvério da Silva (1997).

Na figura 2 são apresentados em forma de gráfico de linha, os resultados dos IS de carbonatos das 11 análises hidroquímicas de água de poços tubulares. Dentre os minerais carbonáticos avaliados (aragonita, calcita e siderita) a grande maioria se encontra levemente subsaturada a subsaturada exceto para a AH6. Estudos de Silvério da Silva (1997) indicaram a ocorrência de calcita de baixo teor de ferro, não sendo confirmada a presença de outros minerais carbonáticos.

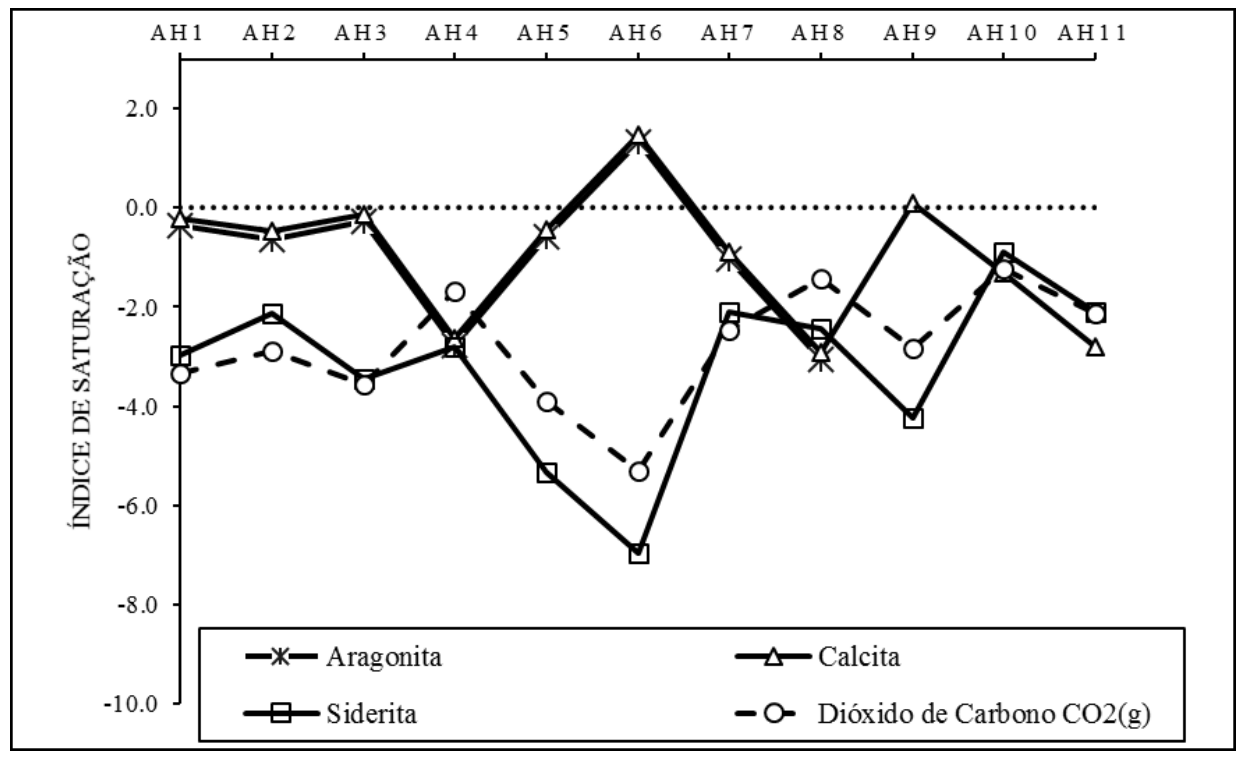

Figura 2 - Gráfico de IS dos minerais carbonáticos e dióxido de carbono

Observando-se os IS calculados, percebe-se a subsaturação dos minerais assim como o gás dióxido de carbono. Ressalta-se que as águas analisadas são pouco mineralizadas com condutividade elétrica, em geral baixa, com média de $269,5 \mu \mathrm{S} / \mathrm{cm}$. Ao analisar a tendência dos IS dos minerais carbonatados, evidencia-se uma relação direta do mineral 
siderita com o dióxido de carbono. Já o oposto observa-se para o restante dos minerais analisados, demonstrando uma relação inversa entre dióxido de carbono e os minerais calcita, aragonita.

Os minerais calcita e aragonita estão muito próximos do equilíbrio (IS $\approx 0)$ haja vista que são materiais comuns em rochas porosas na forma de cimentos, precipitados e/ou como concreções (calcretes) (Silvério da Silva, 1997) e, a ocorrências de dissolução desses materiais são muito comuns em ambientes naturais liberando íons de cálcio. O ataque ácido efetuado pelas águas pluviais nestes materiais é irreversível e ocasiona uma dissolução incongruente (FREEZE; CHERRY, 1979).

Os processos anteriormente descritos são responsáveis pela liberação de íons bicarbonato e carbonato para o ambiente subterrâneo, contribuindo para um aumento sensível dos seus teores na água e consequente aumento do $\mathrm{pH}$, alcalinizando o meio.

\subsection{Minerais sulfatados e sais}

As concentrações de sulfato nas águas subterrâneas das análises hidroquímicas avaliadas variaram de 0,1 a $80,7 \mathrm{mg} / \mathrm{L}$, chegando a valores bem expressivos para AH1 (80,7 mg/L), AH2 (75,1 mg/L) e AH5 (23,4 mg/L). As rochas sedimentares da Formação Santa Maria não contêm minerais com enxofre em sua composição, o que implica, possivelmente, em outras fontes de enriquecimento.

Ao averiguar as possíveis influências de minerais sulfatados provenientes de outras fontes e principais sais para as composições hidroquímicas das águas subterrâneas da área de estudo, calcularam-se os IS para os seguintes minerais: anidrita, gipsita, melanterita, jarosita-K e Alunita. Analisaram-se também, os sais de halita e silvita, representados na tabela 2 .

Tabela 2 - IS de minerais sulfatados e dos sais halita e silvita

\begin{tabular}{|c|c|c|c|c|c|c|c|c|c|c|c|c|}
\hline & Mineral & AH1 & AH2 & AH3 & AH4 & AH5 & AH6 & AH7 & АН8 & AH9 & AH10 & AH11 \\
\hline \multirow{5}{*}{ 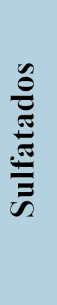 } & Anidrita & -3.2 & -2.71 & -4.41 & -6.14 & -4.53 & -3.97 & -4.01 & -5.78 & -3.78 & -1.24 & -4.75 \\
\hline & Gipsita & -2.84 & -2.36 & -4.05 & -5.78 & -4.18 & -3.61 & -3.65 & -5.43 & -3.48 & -4.21 & -4.45 \\
\hline & Melanterita & -10.3 & -8.71 & -12.1 & -10.66 & -13.80 & -16.7 & -9.59 & -9.66 & -12.6 & -8.43 & -8.52 \\
\hline & Jarosita-K & -7.77 & -5.73 & -9.26 & -16.78 & -13.51 & -14.4 & -9.03 & -15.6 & -14.1 & -11.54 & -10.58 \\
\hline & Alunita & -4.16 & -1.96 & -8.57 & -9.63 & -16.11 & -19.3 & -6.88 & -5.86 & -5.40 & - & - \\
\hline \multirow{2}{*}{$\stackrel{n}{=}$} & Halita & -6.8 & -6.91 & -8.38 & -8.42 & -7.79 & -8.08 & -8.20 & -8.96 & -8.79 & -9.10 & -8.86 \\
\hline & Silvita & -9.45 & -9.53 & -8.98 & -9.45 & -9.58 & -8.43 & -8.31 & -8.70 & -9.01 & -9.06 & -8.65 \\
\hline
\end{tabular}

Nota-se que todos os minerais avaliados estão subsaturados em solução, não sendo possível averiguar uma contribuição significativa dos minerais sulfatados avaliados. No SASM não existe a priori evaporitos ou sulfetos que possam dar origem ao sulfato encontrado nas análises (MANZANO; GUIMARAENS, 2009). As concentrações de sulfato podem estar relacionadas com dois fatores principais, sendo um deles a ocorrência de minerais sulfatados nas formações pré-SAG, como por exemplo a formação Irati que é típica de paleoambiente marinho, através da ocorrência de misturas de águas em fluxo ascendente ou devido a resíduos de decomposição de matéria orgânica superficial.

Os sais halita e silvita mostraram índices de saturação negativos e altos, indicando alta capacidade de dissolução destes sais. Em estudos realizados por MEV foram encontrados microcristalis de halita e silvita em calcretes 
no SASM, no município de Santa Cruz do Sul nos argilitos vermelhos do aquiclude Alemoa (SILVÉRIO DA SILVA, 1997). Contudo, não aparenta influenciar significativamente a química da água subterrânea nas análises avaliadas nesta porção do aquífero.

\subsection{Argilominerais, óxidos e hidróxidos}

Para avaliação dos argilo-minerais, foram calculados os IS para os principais minerais encontrados no aquífero na área de estudo (tabela 3), principalmente para os minerais de alumínio e sílica, sendo albita, ilita, feldspato-k, micak, caulinita e montmorillonita (esmectita). Esses minerais não foram calculados para AH4, AH5, AH8, AH10 e AH11 devido à falta de informação do parâmetro silicato ou alumínio total para essas análises. Apesar disso, ainda é possível observar o comportamento caraterístico das análises remanescentes, principalmente onde o pH é mais alto (AH6).

Tabela 3 - IS dos Argilo-minerais, óxidos e hidróxidos

\begin{tabular}{|c|c|c|c|c|c|c|c|c|c|c|c|c|}
\hline & Mineral & AH1 & AH2 & AH3 & AH4 & AH5 & АH6 & AH7 & AH8 & АH9 & AH10 & AH11 \\
\hline \multirow{6}{*}{ 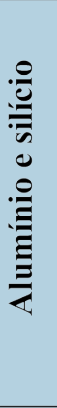 } & Albita & 0.67 & 0.98 & -0.49 & - & - & -2.54 & -2.63 & - & -0.54 & - & - \\
\hline & Ilita & 4.18 & 4.48 & 2.75 & - & - & -1.91 & 0.29 & - & 4.83 & - & - \\
\hline & Feldspato-K & -0.04 & 0.30 & 0.84 & - & - & -0.95 & -0.79 & - & 1.76 & - & - \\
\hline & Mica-K & 10.55 & 11.06 & 9.41 & - & - & 3.11 & 6.66 & - & 11.67 & - & - \\
\hline & Caulinita & 6.21 & 6.82 & 4.32 & - & - & -1.06 & 3.24 & - & 6.31 & - & - \\
\hline & $\begin{array}{l}\text { Montmorillonita } \\
\text { (Esmectita) }\end{array}$ & 9.01 & 9.12 & 6.86 & - & - & 3.89 & 4.06 & - & 8.10 & - & - \\
\hline \multirow{3}{*}{ : } & $\mathrm{Fe}(\mathrm{OH})_{3}$ & 2.12 & 2.15 & 2.08 & -1.31 & 0.93 & 1.72 & 1.04 & -1.61 & -0.15 & -0.03 & -0.23 \\
\hline & Goethita & 7.83 & 7.86 & 7.79 & 4.40 & 6.64 & 7.43 & 6.75 & 4.10 & 5.74 & 5.53 & 5.66 \\
\hline & Hematita & 17.65 & 17.71 & 17.57 & 10.79 & 15.26 & 16.85 & 15.48 & 10.1 & 13.48 & 13.03 & 13.32 \\
\hline \multirow{3}{*}{$\frac{\stackrel{\varrho}{\Xi}}{\stackrel{\Xi}{\Xi}}$} & $\begin{array}{l}\text { Hidróxido de } \\
\text { alumínio }\end{array}$ & -0.23 & -0.15 & -1.25 & -2.48 & -3.50 & -3.50 & -1.80 & -1.91 & -0.54 & - & - \\
\hline & Gibbsita & 2.5 & 2.59 & 1.49 & 0.25 & -0.76 & -0.76 & 0.93 & 0.83 & 2.15 & - & - \\
\hline & $\mathrm{Al}_{2} \mathrm{O}_{3}$ & 1.39 & 1.55 & -0.63 & -2.98 & -5.13 & -5.13 & -1.82 & -2.07 & -1.88 & - & - \\
\hline
\end{tabular}

Os minerais de composição de alumínio e silício apresentaram distintas tendências para a dissolução/precipitação no meio aquoso. Em geral, mostraram tendências de supersaturação com a exceção do feldspato-k que apresentou tendências de equilíbrio. Os argilo-minerais ilita, montmorillonita (esmectita) e caulinita que são elementos comuns encontrados em perfis litológicos do aquífero apresentaram tendências para a supersaturação com a exceção da AH6, que apresentou valores negativos para ilita e caulinita. Esses valores destoantes para a AH6 estão associados ao seu alto valor de $\mathrm{pH}(\mathrm{pH}=10,1)$, uma vez que este parâmetro é determinante nos processos de saturação dos minerais no meio aquoso. 
Alguns minerais apresentaram supersaturação na solução como é o caso dos minerais óxido ferrosos goethita e hematita, indicando uma quantidade de soluto superior a solubilidade para esses minerais. Quando estes minerais ferrosos são atacados por água, o ferro pode ser liberado e novamente reprecipitar. Em ambientes oxidantes as espécies que podem se formar são óxidos férricos ou oxihidróxidos tais como hematita e goethita. Sob condições redutoras de enxofre quando está disponível, podem se formar polissulfuretos ferrosos, tais como a pirita ou marcassita, contudo são espécies menos estáveis (HEM, 1985). Quando o enxofre é menos abundante no meio, a tendência é a formação de siderita (Hem, 1985).

Em geral, soluções supersaturadas são instáveis quimicamente onde a tendência é a precipitação no meio, contudo não é automaticamente equivalente a precipitação pois a solução pode permanecer supersaturada em relação as suas fases minerais por longos períodos de tempo (MERKEL; PLANER-FRIEDRICH, 2012).

Quanto aos hidróxidos de alumínio, verifica-se que estão mais próximos do equilíbrio do que a alunita que é um composto sulfatado e potássico. Isso pode ser explicado pelo fato de que o hidróxido de alumínio é a forma mais estável do alumínio (Hem, 1985) e pela alcalinidade das águas. Contudo, a alunita ainda não foi encontrada em lâminas delgadas microscópicas, podendo, no entanto, ser microcristalina.

Dentre os minerais e os sais com sódio em composição analisados neste estudo, apenas a albita apresentou uma leve supersaturação nas análises $\mathrm{AH} 1$ e $\mathrm{AH} 2$, contudo, isso não explica os altos teores do íon sódio em águas subterrâneas. O sódio é muito solúvel e em ambientes sedimentares pode estar presente em grãos minerais inalterados, na cimentação material, ou na forma de cristais de sais de sódio prontamente solúveis depositado a partir de alguma solução salina (Hem, 1985).

Outros autores como Hanshaw (1964), Hanshaw e Coplen (1973) mostraram experimentalmente que quando compactadas, as argilas adsorvem preferencialmente o sódio e quando dispersas em água adsorvem preferencialmente cálcio. O caráter sódico destas águas pode estar associado ao sódio adsorvido das superfícies dos argilo-minerais presentes nos arenitos do SASM através dos processos de intercâmbio catiônico.

\section{Conclusões}

Devido às diversas reações de dissolução e consequente alcalinização da água, as reações de equilíbrio de carbonatos são deslocadas para direita (direção dos produtos) proporcionando um aumento dos teores do íon bicarbonato. De acordo com Logan (1965), esse processo ocorre até o pH atingir aproximadamente 8,3 e, adicionalmente, o carbonato para valores de $\mathrm{pH}$ maiores do que 8,3.

A dissolução dos minerais carbonáticos consomem íons $\mathrm{H}+$ causando aumento do $\mathrm{pH}$ da água na direção de uma maior alcalinização do meio. Os IS calculados para todas as amostras inferem predominância dos processos de dissolução de minerais, com destaque para os minerais carbonatados.

$\mathrm{O}$ ferro precipita facilmente como $\mathrm{Fe}(\mathrm{OH})_{3}$ e $\mathrm{Fe}_{2} \mathrm{O}_{3}$, assim como os óxidos e hidróxidos de alumínio, podendo provocar processos de cimentação em arenitos, siltitos e lamitos da formação Santa Maria onde o ferro pode trocar de nóx e, portanto, ser liberado do meio para a água subterrânea.

As simulações das reações água/rocha para os argilo-minerais nas análises químicas avaliadas apresentaram supersaturação dos minerais mica-k, caulinita e esmectita. Isso permite inferir que esses minerais estão possivelmente em processo de hidrólise, contribuindo para a liberação de alumínio e sílica no meio e contribuindo para a alcalinização das águas. 
O modelamento geoquímico realizado para este trabalho não detectou supersaturação acentuada de minerais ou sais de sódio das águas subterrâneas do SASM, assim como os minerais sulfatados. É provável que o enriquecimento das águas em sódio deve estar associado ao sódio adsorvido das superfícies dos argilo-minerais através de troca catiônica com a substituição do cálcio em maior concentração do que o magnésio, influenciando a quantidade desses cátions nas águas. Uma característica da água subterrânea bicarbonatada da área do estudo é que as concentrações de cálcio são predominantemente superiores às de magnésio $\left(\mathrm{Ca}^{2+}>\mathrm{Mg}^{2+}\right)$.

Por fim, salienta-se a necessidade do contínuo detalhamento dos processos hidrogeoquímicos de áreas específicas do SAG em estudos científicos, utilizando diferentes técnicas de avaliação, visando a contribuição de informações que possibilitem um melhor entendimento.

\section{Agradecimentos}

Os autores agradecem a Coordenação de Aperfeiçoamento de Pessoal de Nível Superior pela bolsa fornecida ao primeiro autor.

\section{Referências}

APPELO, C.A.J.; POSTMA, D.- Geochemistry, groundwater and pollution, $4^{\circ}$ Ed. Balkema Publishers, Netherlands, 1993. p. 536.

FREEZE, R. A.; CHERRY, J. A. - Groundwater. Prentice Hall, Inc. U.S. 1979. p. 604.

GIARDIN, A.; FACCINI, U. Complexidade hidroestratigráfica e estrutural do Sistema Aqüífero Guarani: abordagem metodológica aplicada ao exemplo da área de Santa Maria-RS, Brasil. Revista Águas Subterrâneas, 18(1). 2004.

HANSHAW, B. B.- Cation-exchange constants for clay from electrochemical measurements: National Conference on Clays and Clay Minerals, 12th, Atlanta 1963, Proceedings. 1964. p. 397-421.

HANSHAW, B. B.; COPLEN, T. B. - Ultrafiltration by a compacted clay membrane--II. Sodium ion exclusion at various ionic exclusion at various ionic strengths. Geochimica et Cosmochimica Acta, v. 37, 1973. p. 2311-2327.

HEM, J. D. - Study and interpretation of the chemical characteristics of natural water. 3.ed: U.S. Geological Survey Water- Supply Paper 2254. 1985. p. 272.

LOGAN, J. The Interpretation of Chemical Analyses of Water. $1^{\circ}$ Ed, U.S. Agency for International Development, 1965.

LUIZ, T. B. B. P.; TERRA, L. G.; SILVA, J. L. S., BORBA, W. F.; FERNANDES, G. D.; GANZER, E. P. - Análise hidroquímica das águas do Sistema Aquífero Guarani na Zona de Afloramentos da região de Santa Maria/ RS. In: VIII SIMPÓSIO BRASILEIRO DE ENGENHARIA AMBIENTAL. Resumos. Curitiba, Paraná, 2015.

MACHADO, J. L. F.; FREITAS, M. A. - Projeto mapa hidrogeológico do Estado do Rio Grande do Sul. Escala 1:750.000, relatório final. Porto Alegre: CPRM. 2005.

MERKEL, B. J.; PLANER-FRIEDRICH, B. - Geoquímica de águas subterrâneas: um guia prático de modelagem de sistemas aquáticos naturais e contaminados. Campinas, SP: Ed. Unicamp, 2012. p. 244.

PARKHURST, D.L.; APPELO, C.A.J.-, User's guide to PHREEQC (version 2)--A computer program for speciation, batch-reaction, one-dimensional transport, and inverse geochemical calculations: U.S. Geological Survey Water-Resources Investigations Report 99-4259, 1999. p. 312. 
PIPER, A.M. -. A graphic procedure in the geochemical interpretation of water analyses. Transactions American Geophysical Union 25. 1944, p. 914-923.

PSAG/OEA/PEA - Projeto de Proteção Ambiental e Desenvolvimento Sustentável do Sistema Aquífero Guarani. Organização dos Estados Americanos. 2009, p. 175.

SIAGAS - Sistema de Informações de Águas Subterrâneas da CPRM, disponível em: http://siagasweb.cprm. gov.br. Acesso em: 15 dez. 2016.

SILVÉRIO DA SILVA, J. L.; MENEGOTTO, E; MEDEIROS, E. R. Avaliação Preliminar dos Argilo-minerais das Folhas de Santa Maria e Camobi, Rio Grande Do Sul, Brasil. Revista Ciência e Natura, Santa Maria, v. 12, 1990. p. 127-132

SILVÉRIO DA SILVA, J. L. Estudo dos processos de silicificação e calcificação em rochas sedimentares Mesozóicas do Estado do Rio Grande do Sul, Brasil. 1997. 157 f. Tese (Doutorado em Geociências) Universidade Federal do Rio Grande do Sul, Porto Alegre. 1997.

J.L.; FLORES, E. M.; BERTAZZO V.M.- Estudo hidroquímico das águas subterrâneas da região de Santa Maria, no Estado do Rio Grande do Sul. In: XXVII CONGRESSO INTERAMERICANO DE ENGENHARIA SANITÁRIA E AMBIENTAL ABES. Porto Alegre: PUCRS, 2000.

SILVÉRIO DA SILVA, J.L.; MENEGOTTO, E. Aspectos Geoquímicos de Silicificações em Rochas Sedimentares no Rio Grande do Sul, Brasil. Pesquisas em geociências, v. 32, n. 2, 2005. p. $29-40$.

SILVÉRIO DA SILVA, J.L.; MENEGOTTO, E. Aspectos mineralógicos de silicificações em rochas sedimentares mesozóicas no Rio Grande do Sul. Revista Brasileira de Geociências, São Paulo, v. 3, n.32, 2002. p. 1-15. 